Thie is BATPAS document

$03--0121$

Call 697-3222/6y' bivis for pickup or return to ang?

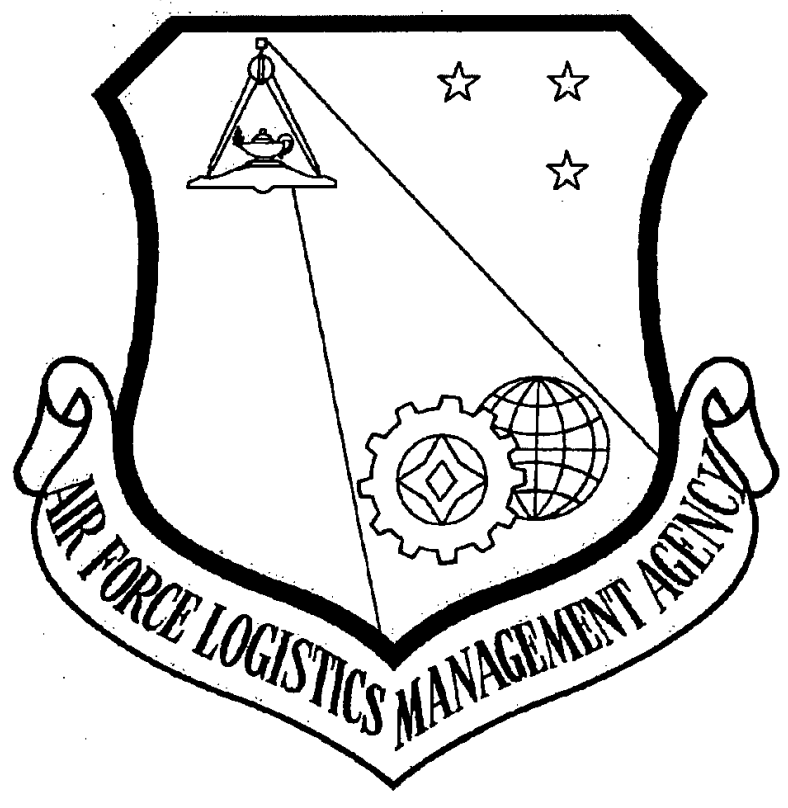

DEPARTMENTOF THE AIR FORCE CLEARED THIS INFORMATION

MAR 172003

FOR PUBLIC RELEASE

\title{
ACCURACY OF BASE-REPORTED ORDER AND SHIP TIME VALUES
}

\author{
AFLMA FINAL REPORT LS200203000
}

\section{SMSGT TONY NICHOLSON AND CAPT CHRIS BOONE}

\author{
Team Members: \\ SMSgt Tony Parrish Major Dave Lyle \\ Dr Doug Blazer (LMI) Dr Steve Reynolds (LMI) \\ Ms Gale Jarnagin
}

Approved for Public Release. Pistribution Unlimited.

AIR FORCE LOGISTICS MANAGEMENT AGENCY

MAXWELL AFB, GUNTER ANNEX AL 36114-3236 
THIS PAGE INTENTIONALLY LEFT BLANK 


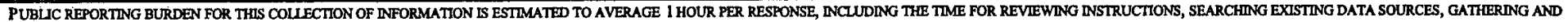
MAŔ

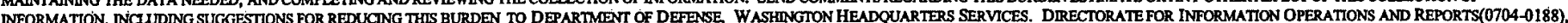

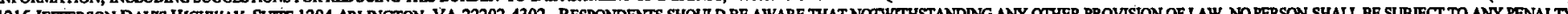
FOR FAIIING TO COMPLY WITH A COLLECTION OF INFORMATION IF IT DOES NOT DISPLAY A CURRENTLY VALDD OMB CONTROL NUMBER. PLEASE DO NOT RETURN YOUR FORM TO THE ABOVE ADDRESS.

1. REPORT DATE 2. REPORT TYPE 3. DATES COVERED (From - To)

May 2002 Final Report February 2002 - May 2002

\section{TITLE AND SUBTITLE}

5A. CONTRACT NUMBER

Accuracy of Base-Reported Order and Ship Time Values

5B. GRANT NUMBER

5C. PROGRAM ELEMENT NUMBER

6. AUTHOR(S)

Capt Christopher A. Boone, AFLMA/LGS, DSN 596-4165

5D. PROJECT NUMBER

5E. TASK NUMBER

5F. WORK UNIT NUMBER

7. PERFORMING ORGANIZATION NAME(S) AND ADDRESS(ES)

Air Force Logistics Management Agency/LGS

501 Ward Street

Maxwell AFB, Gunter Annex AL 36114-3236

9. SPONSORING/MONITORING AGENCY NAME(S) AND

ADDRESS(ES)

HQ AFMC/LGI

4375 Chidlaw Rd, Suite 6, Wright-Patterson AFB , OH 45433-5006

8. PERFORMING ORGANIZATION REPORT NUMBER

LS200203000

10. SPONSOR/MONITOR'S ACRONYM(S)

11. SPONSOR/MONITOR'S REPORT NUMBER(S)

\section{DISTRIBUTION/AVAILABILITY STATEMENT}

13. SUPPLEMENTARY Notes Approved for Publíc Release-

\section{ABSTRACT}

Order and Ship Time (OST) values reported to Readiness Based Leveling (RBL) increased from 9.2 days (October 2001 ) to 10.9 days (January 2002) -- an increase of 1.7 days. A review of base OST values found that many of the values from the January 2002 push were excessively high and most likely inaccurate. Many of these OST values were much greater than truncation points. We also found the SBSS excludes too much receipt data from OST computation. Excluding receipts from airlift investment items also affected base OST -- that is, an accurate OST could not be computed at times because a sufficient number of receipts had not accumulated.

To correct base OST, the AF should modify the SBSS to 1) include receipts for airlift investment items, 2) correct the use of truncation percentages, and 3) correct the initialization problem. In the short-term we propose using a SURGE program to compute base OST. The SURGE will scan base transaction history records each quarter and collect a year of receipt data for both AF and DLA-managed items. The SURGE will apply the correct truncation percentage and generate a file of FCL 3 images. The FCL transactions will then update the base OST data on the routing identifier record with accurate OST data.

\section{SUBJECT TERMS}

Order and Ship Time, OST, O\&ST

\section{SECURITY CLASSIFICATION OF}

A. REPORT

Unclassified

B. ABSTRACT
Unclassified

C. THIS

\begin{tabular}{|c|c|}
\hline 17. LIMITATION & 17. NUMBER \\
OF & OF \\
ABSTRACT & PAGES \\
& 39 \\
4 n-Limited & \\
\hline
\end{tabular}

19. NAME OF RESPONSIBLE PERSON

20. TELEPHONE NUMBER DSN: $596-4165$

STANDARD FORM 298 (REV. 8--98)

PRESCRIBED BY ANSI STD. Z39.18 


\section{THIS PAGE INTENTIONALLY LEFT BLANK}




\section{EXECUTIVE SUMMARY}

\section{BACKGROUND}

Order and ship time (OST) values reported to Readiness Based Leveling (RBL) increased from 9.2 days in October 2001 to 10.9 days in January 2002 , an increase of 1.7 days. A review of base OST values found that many from the January 2002 push were excessively high and probably inaccurate.

\section{PROBLEM STATEMENT}

Inaccurate order and ship times (OST) reported by bases to the readinessbased leveling (RBL) program can cause inaccurate calculation of spares requirements Air Force-wide.

\section{OBJECTIVES}

1. Identify the cause of the inaccurate base-reported OST values.

2. Recommend solutions to correct reporting of base OST.

\section{ANALYSIS RESULTS}

Several discrepancies were found in OST computation. Truncation points (established to exclude depot delay) were being computed incorrectly by the Standard Base Supply System (SBSS), resulting in OST computations using too few receipts and understating OST. Excessive OST values were found on some routing identifier records; the fields required by SBSS for this information had apparently never been initialized since there had never been enough receipts to generate computation of new OST or median values. 
The truncation point errors resulted in fewer receipts being included in OST computation, which requires at least 100 receipts. The lack of included receipts was compounded by the requirement in Air Force Manual (AFMAN) 23-110, USAF Supply Manual, to also exclude airlift investment (AI)-coded items from OST computation. In the past, AI coded items were the only items using fast transportation and thus excluded from OST computation. However, all AFMC-reparable items are now moved via fast transportation, making this policy outdated. The combined effect of these problems was to exclude nearly $90 \%$ of actual base OST data from the OST average computation process, thereby biasing the calculations.

\section{PROPOSAL}

To correct base OST, the AF should modify the SBSS to 1) include receipts for airlift investment items, 2) correct the use of truncation percentages, and 3 ) correct the initialization problem. In the short term we propose using a surge program to compute base OST. The SURGE would apply the correct truncation percentage, include AI items, and overwrite the base OST records with accurate OST data.

\section{CONCLUSIONS}

1) Base-reported OST values are incorrect for three reasons:

a) SBSS incorrectly calculated truncation points.

b) Some fields in base routing identifier records were not initialized. 
c) Too few receipts were used throughout the computation process thereby biasing the calculation of averages.

2) Two days of inaccurately reported OST could generate a requirement for $\$ 43 \mathrm{M}$ in additional pipeline inventory

\section{RECOMMENDATIONS}

1) Long-term: Modify the sBSS to 1) include receipts for airlift investment items in OST computation, 2) correct the use of truncation percentages, 3) eliminate the median value check, and 4) use 25 or more receipts to compute a new average. OPR: HQ USAF/ILGP OCR: HQ SSG/ILS

2) Short-term: Approve the use of a SURGE program to scan base transaction history records each quarter to compute a more accurate OST. The surge should use accurate truncation percentages and include aixlift investment receipts in OST computation and compute OST averages when there are at least 25 receipts.

All recommendations were approved for implementation by the Air Force Stockage Policy Working Group and the Air Force Supply Executive Board. 
THIS PAGE INTENTIONALLY LEFT BLANK 
TABLE OF CONTENTS

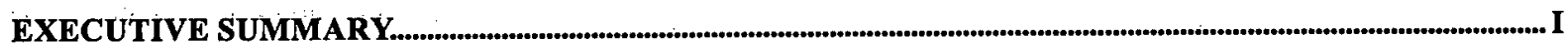

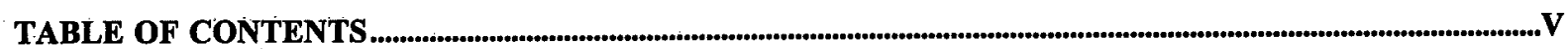

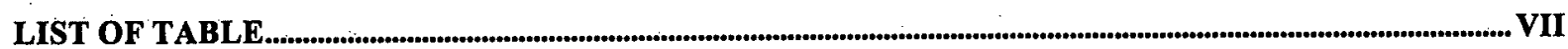

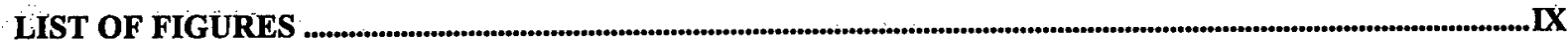

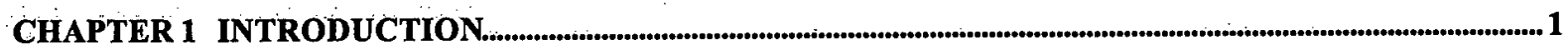

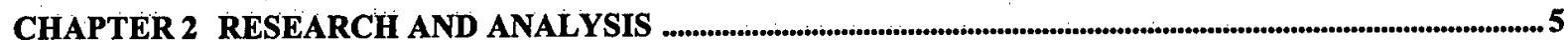

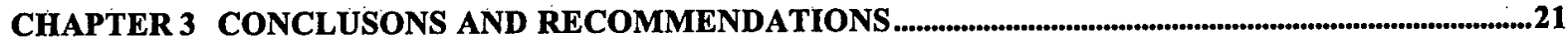

APPENDIX A CURRENT GROUP DATA WITHOUT AIRLIFT INVESTMENT ....................................................23

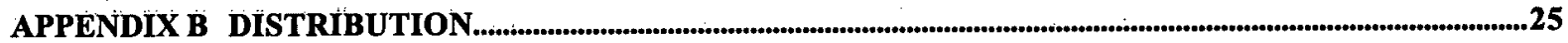


THIS PAGE INTENTIONALLY LEFT BLANK 


\section{LIST OF TABLE}

TABL̇E 1. COMPARISON OF OST ALTERNATIVES TO BASE OST ….............................................................................

TABLE 2. OST TRUNCATION PERCENTAGES - AF-MANAGED ITEMS........................................................................

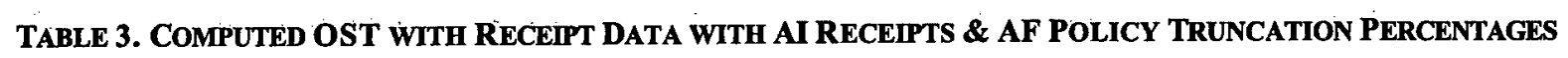
.11

TABLE 4. EXAMPLES OF REPORTED EXCESSIVE OST VALUES ...................................................................................12

TABLE 5. MEDIAN ANALYSIS - CURRENT METHOD ...............................................................................................13

TABLLE 6. MEDIAN ANALYSIS - PRÖPOSED METHOD........................................................................................

TABLE 7. EXAMPLES OF DLA OST COMPARISON ……..........................................................................................15

TABLE 8. EXAMPLES OF DLA TRUNCATION COMPARISON..........................................................................................15

TABLE A-1. COMPUTED OST WITH GROUPED DATA, WITHOUT AIRLIFT INVESTMENT...........................................23 
THIS PAGE INTENTIONALLY LEFT BLANK 


\section{List of Figures}

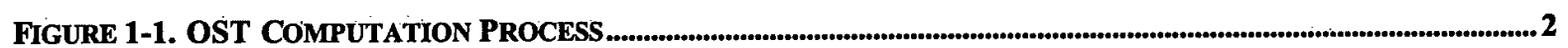

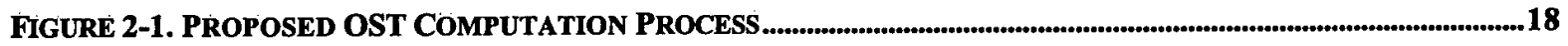


THIS PAGE INTENTIONALLY LEFT BLANK 


\section{CHAPTER 1}

\section{INTRODUCTION}

\section{PROBLEM STATEMENT}

Order and ship time (OST) values reported to the Readiness Based Leveling (RBL) system increased from 9.2 days in October 2001 to 10.9 days in January 2002 , an increase of 1.7 days. A review of base OST values found that many of the values from the January 2002 push were excessively high and probably inaccurate. Inaccurate ost can cause inaccurate AF spares requirements. Therefore, the AFLMA should determine the cause of inaccurate OST and propose a solution that will correct the problem as soon as possible.

\section{BACKGROUND}

Order and ship time is the time elapsed from the submission of a requisition for an item to receipt of the item. At base level, the Standard Base Supply System (SBSS) computes OST for AF reparables (ẌD items) and feeds the data to the Readiness Based Leveling (RBL/D035E) system. D035K also computes and reports OST for AF reparables to RBL at Air Force Materiel Command (AFMC) retail supply accounts. RBL uses the SBSS and D035K OST to allocate base demand levels. It also passes base OST to D2OOA to use in the AF spares requirement computation process. 


\section{Air Force Policy}

The SBSS computes OST quarterly, using cumulative fiscal year data. For example, at the end of December, the SBSS computes OST using 90 days of receipts (Oct - Dec). At the end of March, it uses 180 days of receipt data (Oct - Mar), and so on. Current Air Force (AF) policy for computing OST is to: 1) exclude (truncate) depot delay from OST computation and 2) exclude receipts for airlift investment items. Depot delay is excluded from base OST computation since depot delay is already factored into the requirement computation. We discuss how the SBSS excludes depot delay from OST computation in more detail in Chapter 2. Figure 1-1 describes the current OST computation.

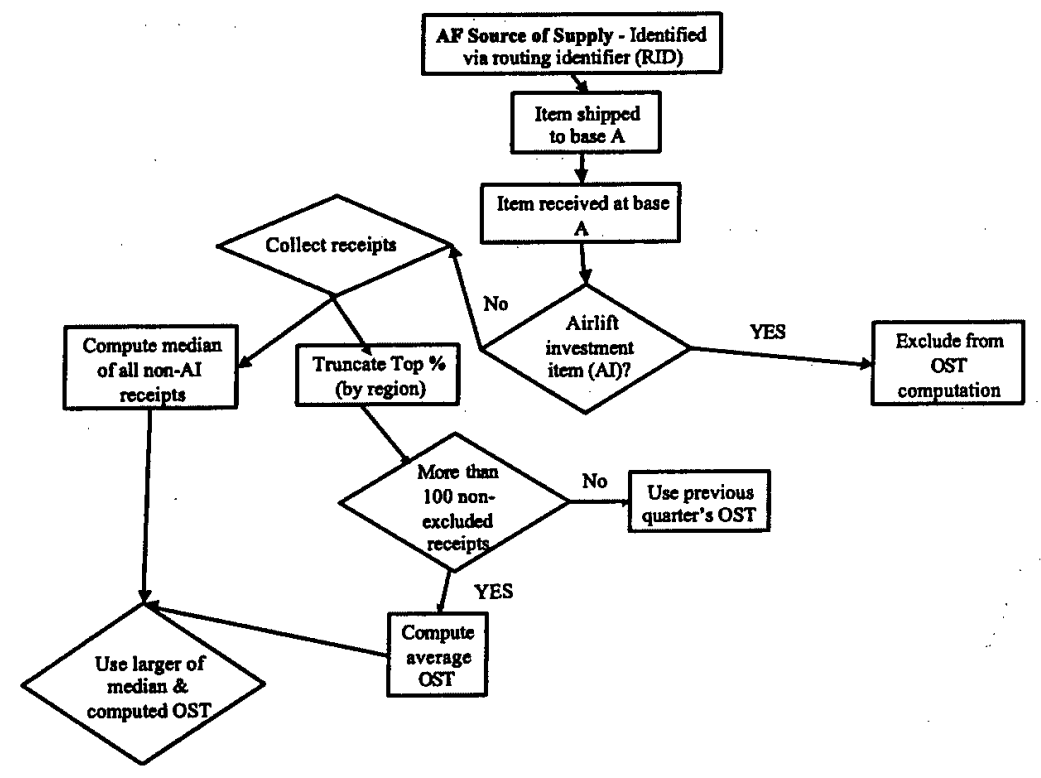

Figure 1-1. OST Computation Process

AF policy is to compute a median OST to compare to the computed quarterly average OST. The median is computed using all receipts 
except AI receipts, while the OST average excludes AI receipts and truncated receipt occurrences (truncated receipts are excluded to remove depot delay time from the OST average). The greater of the two values is the OST reported to RBL. Some constraints must be taken into consideration in computing base OST average and median values. First, a new average OST is computed only when there are at least 100 receipts for each base from a specific source of supply (identified by a routing identifier or RID). Second, the median is used as the new average only when the median is greater than the average and at least 100 truncated receipts have accumulated. For cases where 100 receipts have not accumulated, the OST average from the previous quarter is used and reported.

\section{Airlift Investment}

Current AF policy excludes all receipts for airlift investment-coded items from base OST computation. Airlift investment (AI) was a preLean Logistics initiative for special handling of selected AFMC reparable items--only those items in a buy or repair position. Fast transportation was used for retrograde and requisition shipments of AI-coded items. However, since all AFMC-reparable items are now moved via fast transportation, there is no need to exclude AI items. In fact, excluding the items may result in inaccurate or less accurate OST averages. 
Using AF-wide item record data from the AF Supply Databank, we found 63,000 XD stock numbers loaded at active duty bases in December 2001 . of those, 31,000 (49\%) were coded as airlift investment. The results are more significant when we looked at activity for AF-managed items. Table 1 shows the percentage of receipts AF-wide (active duty bases) for AI-coded items compared to all AF-managed items.

\begin{tabular}{llll}
\hline Total XD NSNs (Dec 2001) & 63,003 & \\
Total AI NSNs (Dec 2001) & 31,345 & $(49 \%)$ \\
Total Receipts for XD NSNs (Oct - Dec 2001) & 105,478 & \\
Total Receipts for AI NSNs (Oct - Dec 2001) & 93,478 & $(89 \%)$ \\
\hline
\end{tabular}

\section{TABLE 1. COMPARISON OF OST ALTERNATIVES TO BASE OST}

As Table 1 shows, receipts for airlift investment items comprised 89\% percent $(93,478$ airlift investment receipts out of 105,478 total receipts) of all receipts for AF-managed reparable items, which means 89\% of actual OST times were not used in the SBSS computation of average OST. Our analysis determined if including airlift investment items in OST computation would change the base-reported OST.

\section{OBJECTIVES}

1. Identify the cause of the inaccurate base-reported OST values. 2. Recommend solutions to correct reporting of base OST.

\section{CONSTRAINT}

Due to the on-going supply modernization effort, programming resources for correcting the OST problems are scarce. Hence, we searched for solutions that would not require sBSS program changes. 


\section{CHAPTER 2 \\ RESEARCH AND ANALYSIS}

\section{METHODOLOGY}

First, we documented the errors in OST computation, measuring the inaccuracy in the currently reported base OST and reviewing the SBSS programs used to compute and report OST. Once the problems were isolated, we looked for ways to correct them. Correcting the problems was not a simple exercise. Due to the on-going supply modernization effort, programming resources for correcting the OST problems are scarce. Hence, we looked for solutions that would not require program changes to the sBSS.

Representatives from three activities (HQ Standard Systems Group [SSG], the Air Force Logistics Management Agency [AFLMA], and Logistics Management Institute [LMI]) conducted the analysis. HQ SSG's analysis focused on reviewing current programs that compute and report base OST and finding the underlying reasons for inaccurate reporting. AFLMA's analysis focused on measuring the level of the inaccuracy in base-reported OST and developing feasible (i.e., nonprogramming) solutions to the problems. LMI was heavily involved in both analyses. AFLMA used the AF Supply Databank as our data source. We analyzed AF-wide base OST data from routing identifier records and receipt transaction history records. We also asked AFMC Directorate of Supply (LGS) to determine the cause of inaccurate D035K-reported 
OSTs. AFMC/LGS personnel suspected the logic for default days 130 days for airlift investment and 90 days for nonairlift items), along with low or no usage data in D035K, caused some of the excessively high OST values. A review of the DO35K logic was ongoing at the time this report was written.

\section{Data Sources}

We examined all active duty bases' routing identifier records from September 2001 since the SBSS uses routing identifier records to accumulate base OST data. We used the routing identifier record OST

group data, as well as actual receipt transaction data, to compute an accurate OST for comparing with the base-computed OST. By group data, we mean the receipt occurrences distributed into buckets in frequency distribution tables based on OST days (e.g., 20 receipts from 1-12 days, 30 receipts from 13-24 days, etc.). We used the current base routing identifier records to determine if the base median and truncation point computations were accurate.

We used receipt transactions from April through september 2001 for four sample bases: Langley AFB, Virginia; Dover AFB, Delaware; Ramstein $A B$, Germany; and Kadena $A B$, Japan. Using receipt data, we computed the actual OST for comparing with base OST reported to RBL and with the OST data stored on base routing identifier records. We also computed truncation points and median values for comparison with truncation and median values currently loaded on the base routing 
identifier record. These comparisons would determine if OST, truncation, and median computations used by the SBSS caused the excessively high base OST reported to $\mathrm{RBL}$.

\section{ANALYSIS RESULTS}

OST increased by almost 2 days from October 2001 to January 2002. We reviewed current base OST data and the programs used to compute and report OST to find the cause of the increase. To determine just how inaccurate base OST really was, we computed the OST using receipt data and current policy and compared it to the current base OST stored on the routing identifier record. We then developed a nonprogramming method to compute and report accurate OST.

\section{Review for Causes of OST Increase in Base Data Reported to RBL.} We analyzed the osT data being fed to RBL. We found nearly 30,000 excessive OSTs reported $(19,533$ for the SBSS accounts and 9,632 for D035K accounts). OST values that exceeded the truncation points were all obviously erroneous. For example, we found 3,734 cases (NSN-SRAN combinations) reporting 96 days as the OST. Next, we looked at the actual routing identifier record from the accounts reporting excessive values. We found the excessive values were stored in the median field of the base routing identifier records. In all these cases, fewer than 100 receipts were recorded. The SBSS should have reported the previous quarter's OST since there were fewer than 100 receipts, but, 
apparently it compared the previous quarter's receipts to the values in the median field and used the larger of the two values.

\section{OST Program Review Results.}

We worked with SSG and LMI analysts to examine the SBSS program code. SSG explained how the SBSS computes and uses OST and identified the cause of the erroneous OST values reported to RBL. They found several OST computation discrepancies. Briefly these include:

- Truncation points were computed incorrectly. For example, at CONUS bases, the SBSS should have truncated (excluded) the largest 33응 of the OST values, from highest to lowest. However, the code truncated the largest $67 \%$ of OST values instead.

- XCB transactions were not created for XF items.

- Override OST values were not used. If the base loaded exception OST, the SBSS continues to report the OST in the routing identifier record (instead of the exception OST).

- High OST values on the routing identifier record will not be overlaid with correct values unless at least 100 receipts are processed.

Although excluding airlift investment receipts was not a discrepancy (current policy excludes airlift investment receipts from OST computation), SSG did identify that the current policy did cause inaccurate OST values since so many receipts are excluded. Due to the truncation problems and exclusion of airlift investment, it was very difficult to get 100 receipts for some routing identifiers at a given base. 
The SBSS uses truncation percentages to exclude receipts, that, theoretically, include depot-delay time from OST computation. Table 2 shows the truncation percentages that AF should be used by area code (location):

\begin{tabular}{clc}
$\begin{array}{c}\text { Area } \\
\text { Code }\end{array}$ & \multicolumn{1}{c}{ Location } & $\begin{array}{c}\text { Truncation } \\
\text { Percentage }\end{array}$ \\
0 & CONUS & $67 \%$ \\
1 & $\begin{array}{l}\text { Alaska (Elmendorf AFB only), Hawaii, N. Atlantic, Caribbean, or Central } \\
\text { America }\end{array}$ & $69 \%$ \\
2 & $\begin{array}{l}\text { U.K. and Northern Europe } \\
\text { Japan (Yokota AB only), Okinawa, Korea (Osan AB only), Philippines, }\end{array}$ & $76 \%$ \\
3 & $\begin{array}{l}\text { Guam, and Western Mediterranean } \\
\text { Hard-Lift Areas - All other destinations not included above (e.g., S. America, }\end{array}$ & $69 \%$ \\
\hline & Eastern Mediterranean, Africa, Diego Garcia, etc.). & $69 \%$ \\
\hline
\end{tabular}

TABLE 2. OST TRUNCATION PERCENTAGES - AF-MANAGED ITEMS

Using Area Code 0 (CONuS bases) as an example, Table 2 shows $67 \%$ of all receipts should be used to compute new OST averages each quarter. The $33 \%$ of occurrences with the highest OST days should be excluded. Instead, for CONUS bases, the SBSS excluded $67 \%$ of the receipts from OST calculations and used only $33 \%$.

Thus, the sBSS erroneously excluded too high a percentage of receipts from OST computation. It does not comply with AF policy. Using the wrong truncation point is a DIREP condition that needs to be corrected for accurate base-reported OST. As we will show later, including receipts for airlift investment would increase the number of receipts used in OST computation. The result would be a more accurate OST. For airlift investment, sBSS programs do comply with policy, but the programs should be changed to include airlift investment receipts. This requires a change to policy. In addition, SSG also found 
excessive OST values on the routing identifier record. These were cases where the fields needed by the SBSS to compute OST were apparently never properly initialized for use. There were simply not enough receipts for these particular base/source of supply/priority group combinations to compute new OST or median values. In fact, we found cases where the median fields contained extremely high values (e.g., 96), apparently due to improper initialization. These uninitialized OST values were eventually reported to RBL. Thus, the three main causes of erroneous OST values were:

1. Truncation point error,

2. Uninitialized values reported as OST, and

3. The exclusion of AI items ( $89 \%$ of the OST occurrences).

\section{Measuring the Impact of Inaccurate OST}

We computed accurate OST for AFMC items to compare to the current, inaccurate, base-reported OST. We used actual receipt data and current policy (i.e., exclude $33 \%$ of receipts for conUs) to compute what the OST should have been. However, we included receipts for airlift investment items to attain a sufficient number of receipts for the computation. Table 3 compares the accurate OST to the current OST on the base routing identifier record. 


\begin{tabular}{ccccccc}
\hline Base & RID & $\begin{array}{c}\text { Receipts Within } \\
\text { Truncation }\end{array}$ & OST Days & $\begin{array}{c}\text { Accurate } \\
\text { OST }\end{array}$ & $\begin{array}{c}\text { Current } \\
\text { OST }\end{array}$ & Difference \\
Langley & FGZ & 326 & 1,979 & 6.07 & 5 & 1.07 \\
& FHZ & 2,075 & 13,752 & 6.63 & 8 & -1.37 \\
Ramstein & FGZ & 151 & 2,125 & 14.07 & 9 & 5.07 \\
& FHZ & 799 & 10,374 & 12.98 & 9 & 3.98 \\
Dover & FGZ & 755 & 6,096 & 8.07 & 6 & 2.07 \\
& FHZ & 1,529 & 12,426 & 8.13 & 5 & 3.13 \\
Kadena & FGZ & 410 & 4,797 & 11.70 & 12 & -0.3 \\
Totals & FHZ & 2,445 & 25,221 & 10.32 & 10 & .32333 \\
\hline
\end{tabular}

TABLE 3. COMPUTED OST WITH RECEIPT DATA WITH AI RECEIPTS \& AF POLICY TRUNCATION PERCENTAGES

Table 3 shows for RID FGZ (a source of supply) at Langley AFB, 326 receipts were within the truncation exclusion and had a total of 1,979 OST days. The accurate, average OST was 6.07 days, but the current system showed an average of only 5 days. Comparing the overall current base average OST to the accurately computed OST showed the accurate average OST was generally higher than the current base OST $(9.04 \mathrm{vs.}$ 8). The SBSS truncated too many receipts and therefore understated the base OST. In this case, low base OST was due to incorrect use of truncation percentages.

The base-reported OST from October 2001 to January 2002 actually increased because of extreme OST values (when fewer than 100 receipts were available). The SBSS does not compute a new OST if a base source-of-supply priority-group combination has fewer than 100 receipts. We found cases where some base/source-of-supply 
combinations had apparently never experienced at least 100 receipts in a year. Thus, fields used to compute OST were apparently nevex properly initialized or prepped by the sBSS. These apparently uninitialized OST fields caused excessive OST values such as those shown in Table 4 .

\begin{tabular}{cccc}
\hline NSN & SRAN & RID_FROM & OST \\
$\mathbf{5 1 2 0 0 1 2 4 2 7 7 7 2}$ & FB5621 & DDQ & 099 \\
$\mathbf{5 8 2 6 0 0 2 5 5 7 0 8 5}$ & FB6540 & DAN & 099 \\
$\mathbf{5 3 0 6 0 1 3 5 7 8 3 6 1}$ & FB6142 & DQV & 098 \\
$\mathbf{5 8 9 5 0 0 0 8 9 4 4 0 3}$ & FB6011 & DMJ & 096 \\
$\mathbf{5 8 2 6 0 0 1 3 4 5 9 7 1}$ & FB6011 & DMJ & 096 \\
$\mathbf{5 8 2 6 0 0 1 3 4 5 9 7 3}$ & FB6011 & DMJ & 096 \\
$\mathbf{5 8 4 1 0 0 1 3 4 5 9 7 5}$ & FB6011 & DMJ & 096 \\
$\mathbf{5 8 2 6 0 0 1 3 4 5 9 7 6}$ & FB6011 & DMJ & 096 \\
$\mathbf{5 8 2 6 0 0 1 3 4 5 9 7 9}$ & FB6011 & DMJ & $\mathbf{0 9 6}$ \\
\hline
\end{tabular}

TABLE 4. EXAMPLES OF REPORTED EXCESSIVE OST VALUES

Including airlift investment receipts in OST computation and correcting the use of the truncation percentages would greatly help alleviate this problem. The erroneously high values caused an overstatement of OST. The uninitialized values were more apparent in the January RBL run because the sBSS used only 90 days of receipt data (the first quarter of FY 2002) highlighting more cases of bases with routing identifiers that had fewer than 100 receipts.

Including airlift investment in OST for reparables and correcting the truncation percentages would significantly increase the number of receipts used to compute OST, thereby causing the SBSS to recompute OST averages each quarter. Therefore, to improve base-reported OST, AF should Include receipts for airlift investment items in reparable 
OST calculations and correct truncation percentages should be used to exclude receipts with depot delay.

\section{Median Analysis}

There was some concern that SBSS-computed median logic is not accurate and sometimes causes reporting of excessive OST values to RBL. Therefore, we examined OST average and median values on base routing identifier records. The median OST is used instead of the computed average whenever it is greater than the calculated average OST and a base routing identifier has at least 100 receipts. Table 5 shows the results of the comparison with current sBSS routing identifier record data.

\begin{tabular}{lccc}
\hline & \multicolumn{4}{c}{ For F $^{* *}$ RID w/ } & 100 receipts or more (97 cases) \\
& Cases & Percent \% & Average Days Difference \\
OST > MED & 10 & 10 & -2.6 \\
MED > OST & 35 & 36 & 3.3 \\
MED $=$ OST & 52 & 54 & 0 \\
& For F & RID w/o 100 receipts (236 cases) \\
OST > MED & 52 & 22 & -5.4 \\
MED > OST & 138 & 58 & 4.7 \\
MED $=$ OST & 46 & 19 & 0 \\
\hline
\end{tabular}

TABLE 5. MEdiAN ANALYSIS- CURRENT METHOD

For routing identifiers with at least 100 receipts, the median was the same or greater than the OST in $90 \%$ of the cases. For cases where the base routing identifier did not experience at least 100 receipts, the median would have been used $58 \%$ of the time, if computed accurately. Frequent use of the median is due, in part, to the truncation percentage problem discussed earlier. The average OST was too low since it truncated $67 \%$ of the OST values instead of $33 \frac{\circ}{\circ}$ and thereby 
understated base OST. Table 6 compares the median computed by the current method to the median computed accurately using AI items and the current truncation percentage.

\begin{tabular}{|c|c|c|c|c|c|c|c|}
\hline $\begin{array}{l}\text { Base } \\
\text { Langley }\end{array}$ & FGZ & $\begin{array}{l}\text { Accurate } \\
\text { OST } \\
6.07\end{array}$ & $\begin{array}{c}\text { Accurate } \\
\text { Median } \\
8\end{array}$ & $\begin{array}{c}\text { Days Median } \\
>\text { OST } \\
1.93\end{array}$ & $\begin{array}{c}\text { Accurate } \\
\text { Median Used } \\
\checkmark\end{array}$ & $\begin{array}{l}\text { Current } \\
\text { Median } \\
8\end{array}$ & $\begin{array}{l}\text { Difference in } \\
\text { Median } \\
\text { none }\end{array}$ \\
\hline Langley & $\mathrm{FHZ}$ & 6.63 & 8 & 1.67 & $\checkmark$ & 8 & none \\
\hline \multirow[t]{2}{*}{ Ramstein } & FGZ & 14.07 & 16 & 1.93 & $\checkmark$ & 21 & +5 days \\
\hline & $\mathrm{FHZ}$ & 12.98 & 14 & 1.02 & $\checkmark$ & 15 & +1 day \\
\hline \multirow[t]{2}{*}{ Dover } & FGZ & 8.07 & 9 & .93 & $\checkmark$ & 8 & -1 day \\
\hline & $\mathrm{FHZ}$ & 8.13 & 10 & 1.87 & $\checkmark$ & 9 & -1 day \\
\hline \multirow[t]{2}{*}{ Kadena } & FGZ & 11.7 & 13 & 1.3 & $\checkmark$ & 9 & -3 days \\
\hline & FHZ & 10.32 & 12 & 1.68 & $\checkmark$ & 10 & -2 days \\
\hline
\end{tabular}

TABLE 6. MEdian ANALYSIS - PROPOSED METHOD

The sample bases' median, when computed accurately, were always greater than the accurate OSTs--on average 1.5 days. Therefore, it appeared using the median artificially inflated OST.

\section{OST for DLA-Managed Items}

We also reviewed sample OST data for DLA-managed items. We found the truncation points for DLA-managed items were overstated, thus causing OST days to be too high. Tables 7 and 8 below show examples of DLA average OST and truncation points (for CONUS bases) compared to OST averages and truncation points we computed. 


\begin{tabular}{|c|c|c|c|c|c|c|c|}
\hline BASE & RID & $\begin{array}{l}\text { AFLMA OST } \\
\text { PG } 1 \& 2\end{array}$ & $\begin{array}{l}\text { SBSS OST } \\
\text { PG 1\&2 }\end{array}$ & 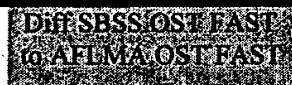 & $\begin{array}{l}\text { AFLMA } \\
\text { OST PG }\end{array}$ & $\begin{array}{c}\text { SBSS OST PG } \\
3 \text { (SLOW) }\end{array}$ & 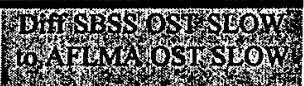 \\
\hline 4469 & S9I & 5.96 & 7 & 104 & 7.67 & 9 & 100 \\
\hline 4661 & s9I & 6.40 & 6 & 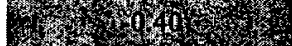 & 9.24 & 9 & Mos \\
\hline 4661 & s9C & 5.11 & 7 & W & 8.89 & 10 & W TI \\
\hline 4661 & S9G & 6.50 & 7 & (x) & 9.56 & 9 & - $>2+1$ \\
\hline 4804 & S9C & 6.09 & 10 & myxhys & 6.89 & 83 & 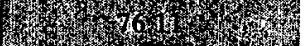 \\
\hline 4809 & S9I & 5.60 & 5 & 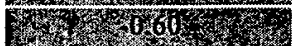 & 10.61 & 11 & 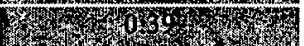 \\
\hline 4852 & s9C & 6.23 & 7 & 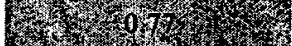 & 8.43 & 9 & 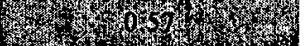 \\
\hline 4852 & S9E & 5.33 & 7 & 157 & 7.77 & 9 & 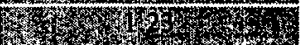 \\
\hline 4852 & S9I & 5.90 & 7 & 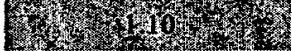 & 8.63 & 10 & $815=6$ \\
\hline 4852 & S9G & 6.77 & 7 & \% & 8.67 & 9 & 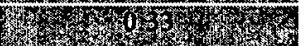 \\
\hline 4872 & S9I & 7.22 & 14 & (x) & 6.68 & 83 & mox \\
\hline 4872 & S9C & 6.48 & 15 & (1) & 6.70 & 83 & 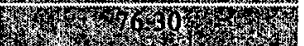 \\
\hline 4897 & S9I & 6.93 & 7 & 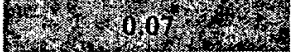 & 9.50 & 9 & 4006 \\
\hline 4897 & S9G & 6.75 & 7 & 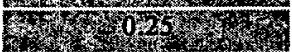 & 9.25 & 9 & 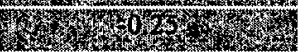 \\
\hline \multicolumn{4}{|c|}{ Average Difference } & 1.84 & & & 16.68 \\
\hline
\end{tabular}

TABLE 7. EXAMPLES OF DLA OST COMPARISON

\begin{tabular}{|c|c|c|c|c|c|c|c|}
\hline BASE & RID & $\begin{array}{c}\text { AFLMA } \\
\text { TRUNCATION } \\
\text { POINT (FAST) }\end{array}$ & $\begin{array}{l}\text { SBSS } \\
\text { TRUNCATION } \\
\text { POINT (FAST) }\end{array}$ & 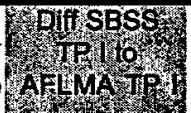 & $\begin{array}{c}\text { AFLMA } \\
\text { TRUNCATION } \\
\text { POINT (SLOW) }\end{array}$ & $\begin{array}{c}\text { SBSS } \\
\text { TRUNCATION } \\
\text { PONTT (SLOW) }\end{array}$ & 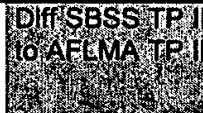 \\
\hline 4469 & S9I & 11.61 & 11 & - & 11.86 & 32 & \\
\hline 4661 & S9I & 12.38 & 15 & W $262,7 x$ & 13.44 & 32 & M \\
\hline 4661 & s9c & 8.10 & 11 & B & 12.66 & 43 & W \\
\hline 4661 & S9G & 11.68 & 32 & $4 \times 2032$ & 13.13 & 30 & W 1687 \\
\hline 4804 & $\mathrm{~s} 9 \mathrm{C}$ & 9.40 & 30 & W 20.607 & 11.27 & 60 & (6) \\
\hline 4809 & s9I & 13.32 & 20 & -146.68 & 14.88 & 49 & 7x+3 \\
\hline 4852 & S9C & 10.57 & 11 & 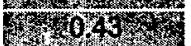 & 12.71 & 17 & \\
\hline 4852 & S9E & 9.01 & 10 & Wry 099 & 11.94 & 14 & \\
\hline 4852 & S9I & 11.62 & 14 & $7 \times 2,38,6$ & 13.28 & 34 & 2012 \\
\hline 4852 & S9G & 11.90 & 15 & 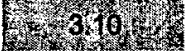 & 13.67 & 40 & 1 \\
\hline 4872 & S9I & 10.52 & 0 & SY 1052 & 10.09 & 0 & 7) 1009 \\
\hline 4872 & S9C & 9.83 & 0 & $f^{2} 983$ & 10.10 & 0 & 6. \\
\hline 4897 & S9I & 11.94 & 16 & Wry 406 & 13.16 & 32 & 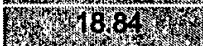 \\
\hline 4897 & S9G & 12.25 & 21 & - & 13.32 & 44 & 420068 \\
\hline $\begin{array}{l}\text { Average } \\
\text { Difference }\end{array}$ & & & & 3.70 & & & 17.96 \\
\hline
\end{tabular}

TABLE 8. EXAMPLES OF DLA TRUNCATION COMPARISON

We suspect the truncation points were inconsistent for DLA-managed

items because the current program used the previous year's data to set 
a truncation point. The 005 program determined the $84^{\text {th }}$ percentile observation value and used that number as the truncation point for the next year's data. Thus, the $84^{\text {th }}$ percentile value with the previous year's data may not be the $84^{\text {th }}$ percentile with the current year's data. Our proposal, which will correct base OST for AF-managed items will also correct OST for DLA-managed items.

\section{SUMMARY}

Base-reported OST was inaccurate. The base-reported OST for AFmanaged items increased almost 2 days from October 2001 to January 2002 (from 9.2 days to 10.9 days) because of initialization problems of OST fields needed to compute OST. Many of these OST values were much greater than truncation points.

The SBSS excluded too much receipt data from OST computation. Excluding receipts from airlift investment items also affected base OST - that is, an accurate OST could not be computed at times because a sufficient number of receipts had not accumulated.

\section{Proposed Solutions}

To correct base-reported OST, the SBSS should be modified to 1) include receipts for airlift investment items, 2) correct the use of truncation percentages, and 3) correct the initialization problem. The first two changes will help resolve the initialization problem. Note that the items will retain their AI identification; the only 
change is that the AI items will be included in OST computation. There could still be sources of supply with fewer than 100 receipts in a quarter even after implementing the first two changes. However, SSG resources are not available to correct the SBSS, code.

In the short-term, we propose using a SURGE program to compute base OST. It would scan base transaction history records each quarter and collect one year's receipt data for both AF-managed and DLA-managed items. It will apply the correct truncation percentage and generate a file of FCL3 images. The FCL transactions would then update the base OST data on the routing identifier record with accurate OST data.

The FCL transaction would only update the OST average; it cannot update the median value (it only updates 3 positions of the 5 -position field that contains both the OST and the median value). The median field would contain all zeros. Therefore, the SBSS would no longer use the median if it exceeds the average OST.

The SURGE program offers some advantages over the current method of computing OST, even if the current method could be corrected. It always uses a year's worth of receipt data. The current (Q05) program uses $90,180,270$, and 365 days of data for December, March, June, and September runs, respectively. The SURGE program will help ensure there are sufficient receipts to compute a new OST average. In addition, the SURGE program will always truncate the right number of 
receipts since it uses the same data to truncate as it does to compute the average. The 005 uses the previous year's data to set the truncation point, then uses that truncation point for the current year. Thus, if OST values are decreasing (or increasing), the current

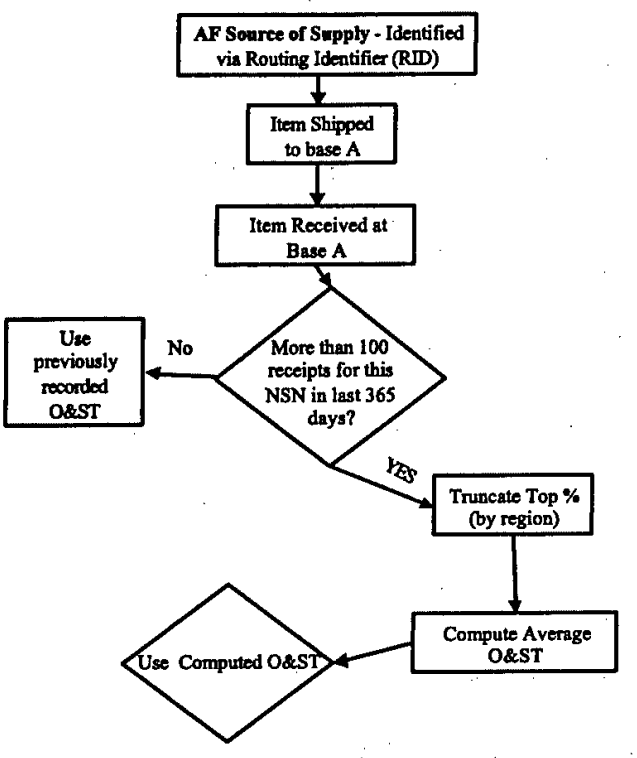

program will truncate too many (or too few) receipts. Figure 2-1 shows the proposed OST computation process.

Figure 2-1. Proposed OST Computation Process

To measure the impact the proposed surge would have on reported OST values, we computed a reasonable approximation of OST using the logic of the proposed SURGE program. We found the current reported OST for AF-managed $(\mathrm{XD})$ items is 10.5 days, an approximation using the SURGE program computes an OST of 7.1 days. 
One concern about the proposed SURGE program is its run-time. The time it would take to scan a year's worth of transaction records may be prohibitive. Therefore, Appendix A provides an alternative program that uses the grouped data already present on the routing identifier record and would result in approximated, but reasonably accurate, OSTs. The grouped data does not include airlift investment receipts, uses less than a year of data, and is an approximation. The SURGE program described in Appendix $A$ is feasible, but definitely inferior to the proposed SURGE.

To ensure a new OST value is computed and reported, we propose that a minimum of 25 receipts be established instead of 100 receipts. The SURGE program then will compute an average OST for AF-managed consumable items using at least 25 receipts for those items coded as using routine transportation (for transportation denial code other than F) and UMMIPS priority of 8 or greater for CONUS bases and 6 or greater for OCONUS bases. OCONUS bases use priority 06 for routine replenishment of stock levels. There still may be a problem recording enough receipts to compute a new OST for AF-managed consumable items. At an average base there are only about 200 AF-managed consumable item NSNs loaded and fewer than 50 of those have any demand land receipt activity). AF-managed consumables are the only AF-managed items that can use routine transportation. So, the priority group 3 (routine) OST only uses receipts for AF-managed consumable items. There may not be 100 receipts in a year. 
THIS PAGE INTENTIONALLY LEFT BLANK 


\section{CHAPTER 3 \\ CONCLUUSIONS AND RECOMMENDATIONS}

\section{CONCLUSIONS}

1. Base-reported OST values are incorrect for three reasons:

a) SBSS incorrectly calculated truncation points.

b) Some fields in base routing identifier records were not initialized.

c) Too few receipts were used throughout the computation process thereby biasing the calculation of averages.

2. Two days of inaccurately reported OST could generate a requirement for $\$ 43 M$ in additional pipeline inventory

\section{RECOMMENDATIONS}

1) Long-term: Modify the SBSS to 1) include receipts for airlift investment items in OST computation, 2) correct the use of truncation percentages, 3) eliminate the median value check, and 4) use 25 or more receipts to compute a new average.

OPR: HQ USAF/ILGP OCR: HQ SSG/ILS

2) Short-term: Approve the use of a SURGE program to scan base transaction history records each quarter to compute a more accurate OST. The surge should use accurate truncation percentages and include airlift investment receipts in OST computation and compute OST averages when there are at least 25 receipts. 
OPR: HQ USAF/ILGP OCR: HQ SSG/ILS

All recommendations were approved for implementation by the Air Force Stockage Policy Working Group and the Air Force Supply Executive Board.

\section{BENEFITS}

1) Accurate OST allows for accurate computation of AF buy and repair requirements.

2) Correcting the OST error allows the AF to avoid the additional $\$ 43$ million in requirements created by just 2 days increase in OST. 


\section{APPENDIX A \\ Current Group Data Without Airlift Investment}

We were concerned the run-time for the proposed SURGE program would be excessive. This appendix presents an alternative SURGE program that does not require a transaction history scan; thus, the SURGE run-time could be reduced. This method uses current group OST data from the frequency distribution tables from base routing identifier records to compute OST. Therefore, it uses data that did not include receipts for airlift investment items. We tried this method to determine if using current group data could provide a reasonably accurate average OST using data stored on base routing identifier records. Table A-1 shows an example of computing OST at four bases using this alternative:

\begin{tabular}{|c|c|c|c|c|c|c|c|c|c|c|c|c|}
\hline \multirow[t]{2}{*}{ Base } & \multirow{2}{*}{ RID } & \multicolumn{2}{|c|}{ Pri Groúp 1\&2 } & \multirow{2}{*}{$\begin{array}{l}\text { Days 1-12 } \\
\text { Weighted } \\
\text { OST Days }\end{array}$} & \multicolumn{3}{|c|}{ Pri Group 1\&2 Days 13-24 } & \multicolumn{3}{|c|}{ Pri Group 1\&2 Days 25-26 } & \multirow[b]{2}{*}{$\begin{array}{l}\text { Group } \\
\text { OST }\end{array}$} & \multirow[b]{2}{*}{$\begin{array}{c}\text { Accurate } \\
\text { OST }\end{array}$} \\
\hline & & Receipts & $\begin{array}{c}\text { Mid } \\
\text { Point }\end{array}$ & & Receipts & $\begin{array}{l}\text { Mid } \\
\text { Point }\end{array}$ & $\begin{array}{l}\text { Weighted } \\
\text { OST Days }\end{array}$ & Receipts & $\begin{array}{l}\text { Mid } \\
\text { Point }\end{array}$ & $\begin{array}{l}\text { Weighted } \\
\text { OST Days }\end{array}$ & & \\
\hline \multirow[t]{2}{*}{ Langley } & FGZ & 60 & $6 . \dot{5}$ & 390 & 9 & 18.5 & 166.5 & 0 & 25.5 & 0 & 8.07 & 6.07 \\
\hline & FHZ & 223 & 6.5 & 1449.5 & 27 & 18.5 & 499.5 & 3 & 25.5 & 76.5 & 8.01 & 6.63 \\
\hline \multirow[t]{2}{*}{ Dover } & FGZ & 59 & 6.5 & 383.5 & 5 & 18.5 & 92.5 & 0 & 25.5 & 0 & 7.44 & 8.07 \\
\hline & FHZ & 65 & 6.5 & 422.5 & 7 & 18.5 & 129.5 & 2 & 25.5 & 51 & 8.15 & 8.13 \\
\hline \multirow[t]{2}{*}{ Ramstein } & FGZ & 22 & 6.5 & 143 & 35 & 18.5 & 647.5 & 2.5 & 25.5 & 63.75 & 14.36 & 14.07 \\
\hline & $\mathrm{FHZ}$ & 36 & 6.5 & 234 & 17 & 18.5 & 314.5 & 1.5 & 25.5 & 38.25 & 10.77 & 12.98 \\
\hline \multirow[t]{2}{*}{ Kadena } & FGZ & 53 & 6.5 & 344.5 & 7 & 18.5 & 129.5 & 5 & 30.5 & 152.5 & 9.64 & 11.7 \\
\hline & FHZ & 153 & 6.5 & 994.5 & 28 & 18.5 & 518 & 14 & 30.5 & 427 & 9.95 & 10.32 \\
\hline
\end{tabular}

TABLE A-1. COMPUTED OST WITH GROUPED DATA, W ITHOUT AIRLIFT INVESTMENT

Table A-1 shows that for a sample of 8 bases, (base routing identifier combinations) using the current routing identifier record data, the grouped data was reasonably close to the accurate OST. For example, at Langley for FGZ, the grouped data resulted in an average OST of 8 
days versus the 6-day accurate OST. Using grouped data was not as accurate, but it could be used if necessary. However, the problem remains of excluding airlift investment items and thereby not having sufficient sample size to provide a more accurate average. Grouped data should only be used as a last resort--if the run time to scan transaction history data is prohibitive. 


\title{
Appendix B
}

\section{Distribution}

\begin{abstract}
HQ USAF/IL
HQ USAF/ILG

HQ USAF/ILM

SAF/AQC

HQ AFMC/LG

HQ ACC/LG

HQ AMC/LG

HQ AMC/DDO

HQ AFRC/LG

HQ USAFE/IG

HQ PACAF/LG

HQ AETC/LG

HQ AFSOC/LG

HQ AFSPC/LG

ANG/LG
\end{abstract}

